\title{
EDITORIAL
}

\section{Off-label prescribing: a matter of trust}

A whistleblower lawsuit filed against Wyeth (now owned by Pfizer) alleges that the company promoted improper off-label marketing of its immunosuppressant agent Rapamune ${ }^{\circledR}$ (sirolimus), which is used to prevent rejection in renal transplantation (http://op.bna.com/hl.nsf/id/deln-85ts8f/\$file/ rapamune52410.doc.pdf). Former Wyeth sales representatives say that they were encouraged to promote several unapproved Rapamune ${ }^{\circledR}$ protocols, including use of the agent in non-kidney transplant recipients, in high-risk patients, in conversion protocols, and with unapproved combinations of drugs.

The prescribing of approved drugs for unapproved purposes is legal. Many examples exist in which this practice has benefited patients and led to therapeutic advances. The potential benefits achieved by off-label prescribing are clearly recognized by the FDA, which published new "good reprint practice" guidelines for the distribution of information on unapproved uses for approved drugs in 2009 (http://www.fda.gov/regulatoryinformation/ guidances/ucm125126.htm).

Although the marketing of off-label uses remains illegal, the new FDA guidelines seem to reflect a more permissive attitude than previous strategies. For instance, before the introduction of the FDA Modernization Act in 1997, the dissemination of information on non-FDAapproved drugs was disallowed. The FDA Modernization Act permitted the distribution of literature with FDA pre-approval. In 1999, this act was amended so that companies could distribute literature on off-label uses on the provision that the distributing company intended to submit an application to the FDA for the approval of that new use. These regulations lapsed in 2006.

The FDA states that the new guidelines recognize that "articles that discuss unapproved uses of FDA-approved drugs and devices can contribute to the practice of medicine". They aim to aid the dissemination of "truthful and non-misleading" scientific literature on off-label uses of approved drugs while "safeguarding" against off-label promotion (http://www.fda.gov/newsevents/newsroom/ pressannouncements/2008/ucm116859.htm). The 2009 guidelines recommend that scientific literature is provided to clinicians separately from promotional information, is representative of the available literature, and is accompanied by contradictory studies if available. In essence, the FDA recommends that the dissemination of information on unapproved uses for approved medications is as transparent as possible, enabling physicians to decide the best treatment on the basis of available evidence.

According to the lawsuit filed against Wyeth, however, the promotion of off-label indications for Rapamune ${ }^{\circledR}$ was anything but transparent. The whistleblowers claim that sales representatives were encouraged to selectively present data and withhold clinical information on the harmful adverse effects of Rapamune ${ }^{\circledR}$ in order to make claims that were not supported by scientific literature. For example, Wyeth allegedly encouraged sales representatives to promote Rapamune ${ }^{\circledR}$ as an anti-rejection drug for non-kidney transplants, including liver, heart, lung and pancreas transplants, despite the presence of 'black box' warnings issued by the FDA against the use of this agent in liver and lung transplant recipients. Similarly, the whistleblowers say that Wyeth encouraged sales representatives to promote Rapamune ${ }^{\circledR}$ in conversion protocols, despite a lack of supporting data and despite the fact that the FDA issued a warning against this practice owing to a risk of adverse events. The administration of Rapamune ${ }^{\circledR}$ with unapproved combinations of drugs was also encouraged, say the whistleblowers. The obvious purpose of off-label marketing is to expand a drug's market and therefore its revenue. Not surprisingly, the whistleblowers claim that off-label marketing by Wyeth increased market sales-in the third quarter of 2002 , only $17 \%$ of Rapamune ${ }^{\circledast}$ was used as directed.

Off-label prescribing is common in many areas of medicine, but it is the lack of supporting evidence for the safety and efficacy of many indications that is particularly disconcerting. In one study, $73 \%$ of off-label drug uses had little or no scientific support (Radley, D. C. et al. Arch. Intern. Med. 166, 1021-1026; 2006). Clinicians need access to unbiased scientific literature to make evidence-based recommendations and to provide the most safe and effective treatment to patients. The risks associated with off-label uses must therefore be clearly conveyed by the distributing company. Disappointingly, several major drug companies have been fined over the past few years for illegal off-label marketing practices, suggesting that this need has not been met.

The 2009 FDA guidelines are well intended; however, they may fall short of their goal. Their relaxed and nonbinding nature provides companies with the freedom to distribute information on off-label uses to clinicians and trusts the pharmaceutical companies to ensure that the literature they distribute is unbiased. The new guidelines should be welcomed for attempting to improve clinical decision making, but policing the guidelines will be paramount to their success. The FDA must be prepared to tighten regulations if pharmaceutical companies continue to place patients at risk by illicitly promoting off-label uses. Once trust has been lost it is difficult to regain.

doi:10.1038/nrneph.2010.104

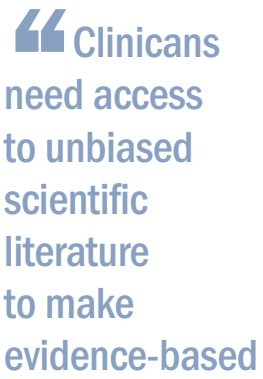

recommendations... 77

Susan J. Allison is the Chief Editor of Nature Reviews Nephrology.

Competing interests The author declares no competing interests. 